\title{
REDUCTION OF RADIAL THRUST BY USING TRIPLE-VOLUTE CASING
}

\author{
E. M. Mina R. N. Abdelmessih and M. E. Matbouly \\ Mech. Power Eng. Dept., Faculty of Eng., Ain Shams University, Cairo, Egypt.
}

\begin{abstract}
Radial thrust in a single volute centrifugal pump, which is a result of pressure variation in the volute casing, is investigated in order to avoid failures caused by this thrust force. Two ideas are introduced to avoid or to minimize this thrust force, the first is a double volute, and the second is a triple volute. A complete centrifugal pump design was manufactured. The volute was designed such that partition vanes could be added to change the number of volutes. Experiments were performed on single volute centrifugal pump, double volute centrifugal pump and triple volute centrifugal pump at 500, 800, and $900 \mathrm{rpm}$ for each case. The thrust values of the double volute pump are always lower than that of the single volute pump specially when operating far from the best efficiency point where, the radial thrust is reduced by more than $55 \%$ at shut off and more than $40 \%$ at high discharges, while the thrust values of the triple volute are always lower than that of the single volute and double volute pumps specially when operating far from the best efficiency point where, the radial thrust is reduced by more than $70 \%$ at shut off and more than $50 \%$ at high discharges comparing to single volute and the radial thrust is reduced by more than $40 \%$ at shut off and more than $20 \%$ at high discharges comparing to double volute . However, it is to be mentioned that the best pump efficiency is always obtained for the single volute pump, compared with the other alternatives.
\end{abstract}

Key words : Radial thrust, double volute, centrifugal pump, pressure distribution Nomenclature

\begin{tabular}{|c|c|c|}
\hline$B_{i}$ : width of the impeller & [m] & I : line current \\
\hline BP: Break Power & {$[\mathrm{kW}]$} & K: experimentally coefficient $\quad[-]$ \\
\hline BEP : the best efficiency point & {$[-]$} & N: Rotational Speed \\
\hline $\cos \varphi$ : Motor power factor & [-] & $P_{\mathrm{d}}:$ pump discharge pressure. [barg] \\
\hline $\mathrm{C}_{\mathrm{Q}}:$ flow coefficient & {$[-]$} & Ps: pump suction pressure $\quad$ [barg] \\
\hline $\mathrm{C}_{\mathrm{H}}$ : Head coefficient & {$[-]$} & Q: flow rate \\
\hline $\mathrm{C}_{\mathrm{P}}$ : Power coefficient & {$[-]$} & $Q_{n}:$ discharge at BEP \\
\hline$D_{\mathrm{i}}:$ outside diameter of impeller & [m] & sp. gr.: specific gravity \\
\hline$F_{\mathrm{r}:}$ The radial thrust force & {$[\mathbf{N}]$} & $\mathrm{V}$ : line to line voltage \\
\hline g : Gravity acceleration & {$\left[\mathrm{m} / \mathrm{sec}^{2}\right]$} & $\eta_{\text {motor }}:$ motor efficiency \\
\hline H: pump head & [m] & $\eta_{\text {pump: }}:$ pump efficiency \\
\hline $\mathrm{H}_{\mathrm{v}}$ : Velocity Head & {$[\mathrm{m}]$} & $\Theta$ : Angle measured from tongue [deg] \\
\hline $\mathrm{H}_{\mathrm{z}}$ : Elevation Head & [m] & $\rho$ : Density of water $\quad\left[\mathrm{kg} / \mathrm{m}^{3}\right]$ \\
\hline
\end{tabular}

\section{INTRODUCTION}

The volute casing of a centrifugal pump is designed such that it maintains a uniform pressure distribution on the impeller. Once the pump departs the best efficiency point, BEP, this uniformity in pressure is no more ensured. And hence, the impeller, and consequently the shaft, are subject to a resultant radial force. This force is more pronounced as the departure from the BEP is increased, especially at the shutoff point, and might cause failure in bearings or break the shaft. 
Stepanoff [1], introduced the following equation that correlates lateral force to the impeller geometry and predicts the value of radial thrust;

$$
\mathrm{F}_{\mathrm{r}}=\mathrm{sp} \cdot \mathrm{gr} \cdot \mathrm{KHD}_{\mathrm{i}} \mathrm{B}_{\mathrm{i}}
$$

Where sp. gr. is the specific gravity and equals 1 for water at ambient condition.

Igor J. Karassik et al. [2], showed that the values of K coefficient were determined by Agostinelli et al [3], as a functions of specific speed and flow rate. He also got an estimation for the direction of Fr. The radial thrust is usually minimum at the best efficiency point (BEP). He also compared the results obtained from a single volute pump and another double volute one. It was found that $\mathrm{K}$ is minimum at $\mathrm{Q}=\mathrm{Qn}$, where $\mathrm{Qn}$ is the discharge at $\mathrm{BEP}$, and as the pump depart from the $\mathrm{BEP}$, the radial thrust increases till it reaches the maximum value at shut-off. Also, the values of radial thrust of the double volute pump were always smaller than that of the single volute pump. This reduction is more pronounced at off-design conditions; where the radial thrust values are high and considered a problem. According to Agostinelli et al.[3], the direction of the radial thrust in double-volute casings was found to be generally toward the casing tongue. Lebanof et al [4]; performed experimental studies to get the optimum radial rib length (minimum radial force). Mazhar [5], experimentally investigated the length of the partition vane at 2000, 2250, and $2500 \mathrm{rpm}$. He showed that a partition vane that extends to $90 \%$ of the length gives the best efficiency, and the minimum radial thrust is obtained between 90 to $95 \%$ of the total length. Baun et.al [6] investigated the use of circular casing instead of the volute casing. The optimum geometry that results in the best efficiency and minimum radial force was found through several experiments. A patent was published in 2006 [7], about perforated double volute. The effect of perforation on the noise and ease of manufacturing was highlighted. Weaver et al. [8], reported the results of an experimental study of the pressure pulsations produced by a centrifugal volute pump at its blade passing frequency. Detailed measurements were made for the pressure fluctuations in the piping as a function of pump rotational speed and flow rate. The effects of changing tongue profiles were studied. M. Behzad et.al. [9], has carried out vibration measurement in different conditions in order to find the main reason for excessive vibration of the pumps.

Agostinelli et al [3], performed an experimental investigation to determine the magnitudes and directions of the unbalanced radial forces on centrifugal pump impellers by using strain gages. The work covers single volutes for a wide range of specific speed, double volutes, concentric casings, and modifications of the concentric casing. These results will be used for comparison in the results section. Aoki [10], studied the fluctuating of radial thrust on single-blade centrifugal pumps handling waste water with solids, by measuring instantaneously pressure distribution close to the impeller discharge along the impeller periphery affected by volute pressure distributions on the suction cover surface of a pump with an open-type centrifugal impeller having one blade. The fluctuating radial thrust mechanism has been clarified on the basis of these measurements, and a difference between actual radial thrust and the integrated value of static pressure along the impeller outlet was discussed. It was found that at best efficiency point the radial thrust force vector has a circle with center at origin, and off-best efficiency point it has an eccentric ellipse.

With the increase in computer capabilities, several researches dealt with several aspects of pump design, including volute casing. Gonzalez [11,12] for example studied the effect of unsteady component of the flow on the radial force and revealed that the dynamic component of the radial thrust may be more significant than the static force. Guo et.al., [13], studied the clearance area between impeller and volute in a low specific speed centrifugal pump equipped with three different impellers outlet diameter and variable cut-water geometry. The numerical study results indicated that the maximum efficiency point is shifted along the lower flow rate direction with the increasing of impeller-volute radial gap.

As shown in the previous work mentioned above some of them were studying experimentally volute shape and type, radial rib length and changing tongue profiles and the others studying pump design by using numerical simulations techniques to reduce the radial thrust force in centrifugal pumps, but no previous researches found studying experimentally the triple volute casing design to reduce the radial thrust force which is studied in this paper. 


\section{Material and Method}

\section{1- pump design}

The pump was designed to deliver $54 \mathrm{~m}^{3} / \mathrm{hr}$ against $10 \mathrm{~m}$ head. The procedure described in Church[14] was followed and resulted in an impeller with 7 blades and $29.5 \mathrm{~cm}$ outer diameter with a blade exit angle of $30^{\circ}$. For the simplicity in manufacturing and assembling of the pump and volute, we chose constant width for the whole pump. The complete dimensions of the impeller are shown in figure $1 \mathrm{~A}$.
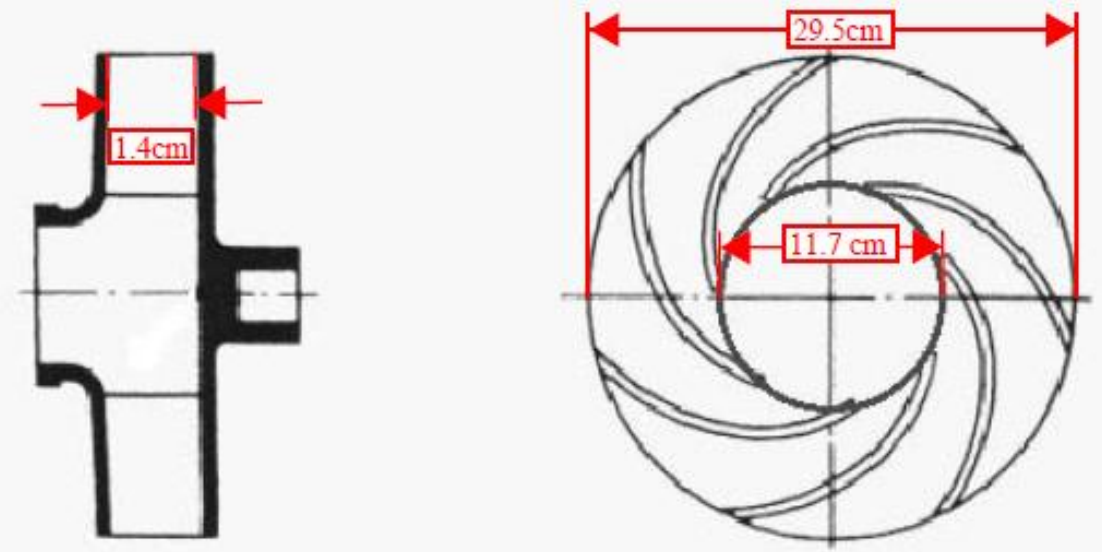

Fig. 1A,pump impeller drawing

The volute was designed to accept partition vanes to operate as single, double, and triple volute.

Figure 1B shows the volute, with the setting of each case colored in different color.

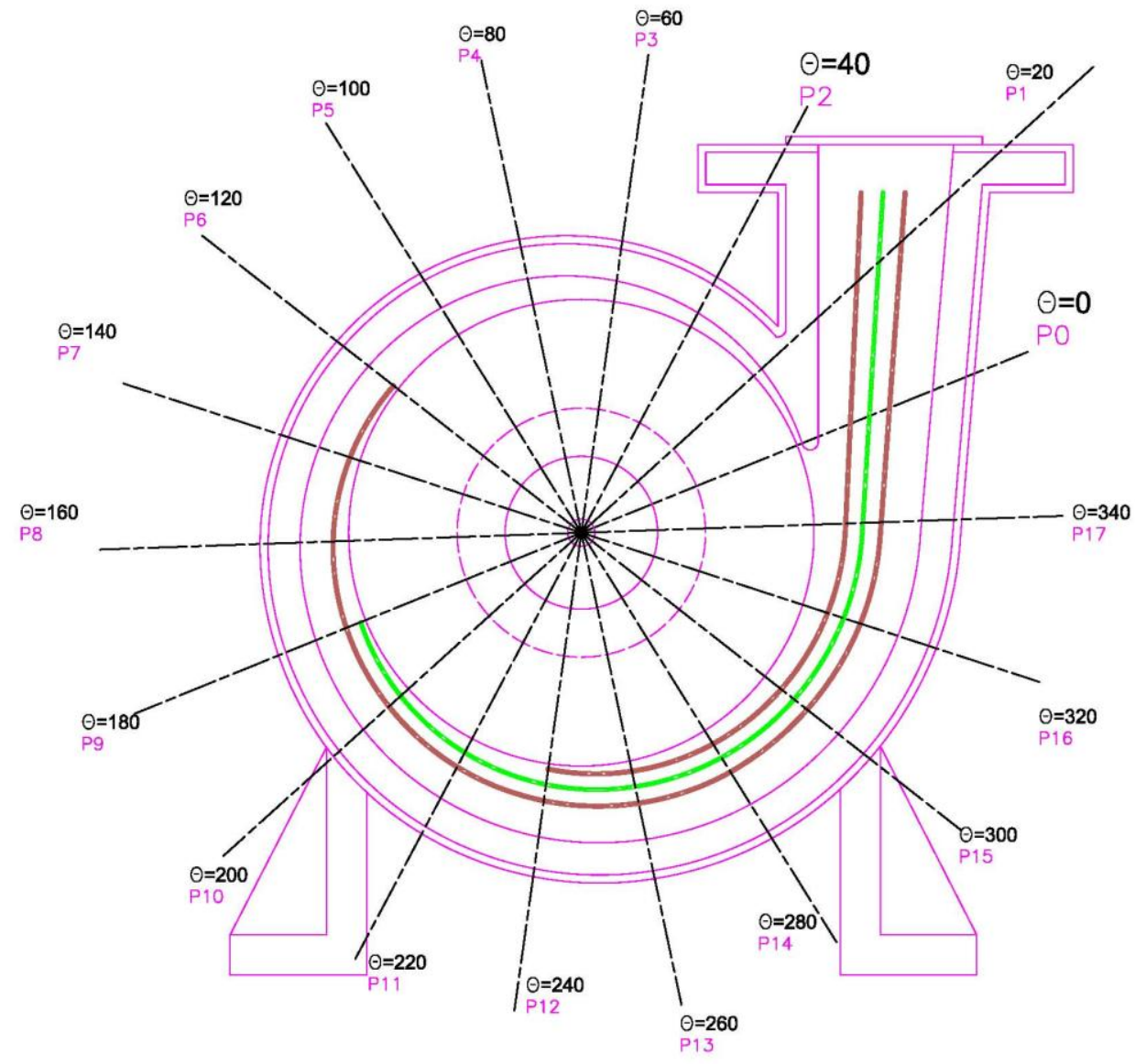

Fig. 1B, pump volute design drawing showing points of pressure measurements.

\section{2-Test setup}

A test rig was designed and set up to test the manufactured pumps at three different speeds 500, 800 , and 900. The setup shown in Figure $2 \mathrm{~A}$ and $2 \mathrm{~B}$, consists of the pump driven by a $30 \mathrm{hp}$ electric motor. The pump is connected to a large elevated open tank about $1.5 \mathrm{~m}$ higher than the 
pump intake and a discharge pipe that discharge back to the inlet tank. Pressure gauges are connected to both inlet and exit flange. Pressure gauges are also connected to 17 points along the back side of the volute casing close to the impeller discharge to monitor the pressure distribution along the impeller periphery as shown in figure 1B. The electric motor receives 3 phase current through a digital panel that controls the motor speed and monitors the voltage, current, and phase shift. A flow meter with minimum count of $0.01 \mathrm{~m}^{3}$ and a stop watch are used to estimate the pump discharge. A tachometer is used to measure the motor rotational speed.

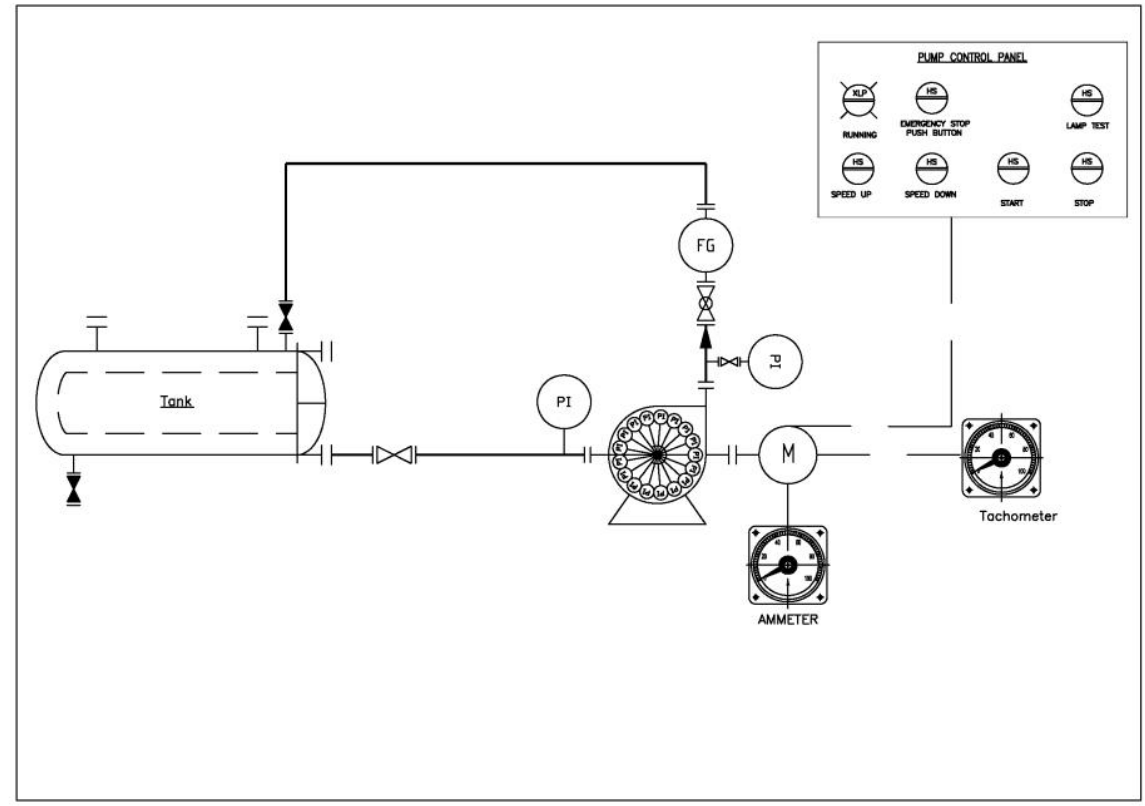

Fig. 2A, Schematic diagram for Test rig

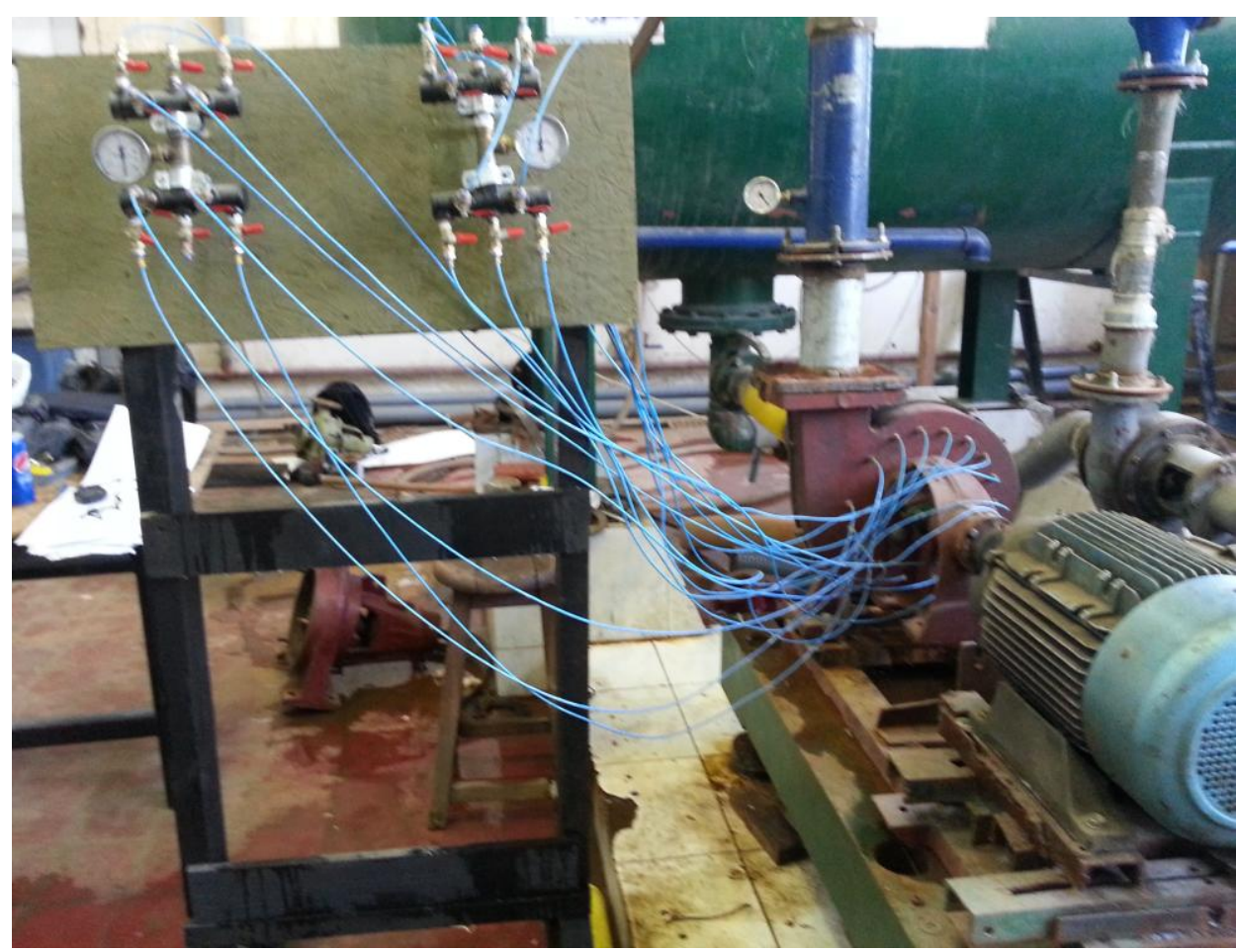

Fig. 2B, picture for test rig

\section{3- Data reduction/ Calculations}

Experiments are performed on the three pump volutes (single volute centrifugal pump, double volute centrifugal pump, and triple volute centrifugal pump). For each run a valve is used to change the load on the pump. For each valve opening the head is calculated from the 
following equation:

$H=\frac{P_{d}-P_{s}}{\rho g}+H_{v}+H_{z}$

The discharge $\mathrm{Q}$ is estimated by recording the difference in the flow meter reading in a time interval.

The power drawn by the motor is calculated from:

$$
B P=\sqrt{3} V I \cos \emptyset \eta_{\text {motor }}
$$

and hence the efficiency is estimated by dividing the fluid power over the brake power:

$\eta_{\text {pump }}=\frac{\rho g Q H}{B P}$

The curves of the performance are plotted in non-dimensional form the head, flow, and power coefficients are defined as in the following equation

$$
\begin{aligned}
& C_{H}=H g / D^{2} N^{2} \\
& C_{Q}=Q / N D^{3} \\
& C_{P}=B P / \rho N^{3} D^{5}
\end{aligned}
$$

The components of the thrust force are calculated from integrated the forces on all segments of the impeller periphery

$$
\begin{aligned}
& F_{x}=\int P_{i} \pi d B \cos \theta_{i} \\
& F_{y}=\int P_{i} \pi d B \sin \theta_{i}
\end{aligned}
$$

The resultant force and its direction are calculated from the following equation:

$$
\begin{aligned}
& F=\sqrt{F_{x}^{2}+F_{y}^{2}} \\
& \theta=\tan ^{-1}\left(F_{x} / F_{y}\right)
\end{aligned}
$$

\section{Results}

\section{1-Pump performance}

The above described procedure was used to access the pump performance, Figure 3 shows the performance of a single volute pump. The points corresponding to different speed overlap and could be represented as one curve on the non-dimensional scale. Figure $3 \mathrm{~A}$ represents the relation between the head and flow coefficient. The shut off head coefficient is around 5, while the maximum flow coefficient is 0.048 . The power coefficient is presented in figure $3 \mathrm{~B}$ : it is noticed that the brake power increase continuously as the discharge increases. The efficiency represented in figure $3 \mathrm{C}$ shows that the best efficiency is always around 0.025 . The efficiency increased as the rotational speed increased. 


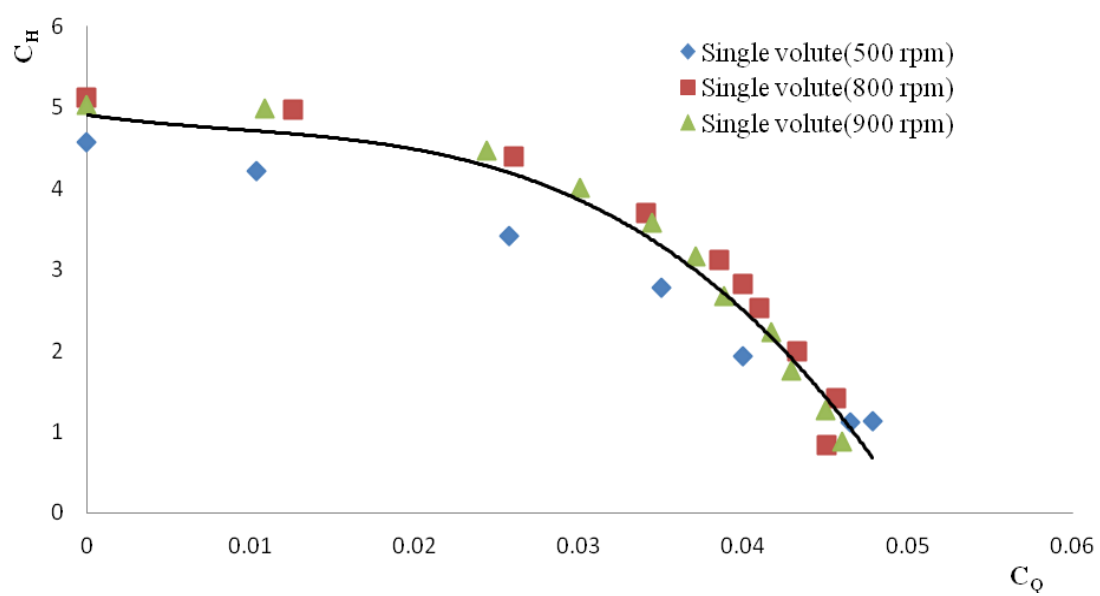

Fig. 3A, Head coefficient (CH) versus flow coefficient (CQ) for single volute pump

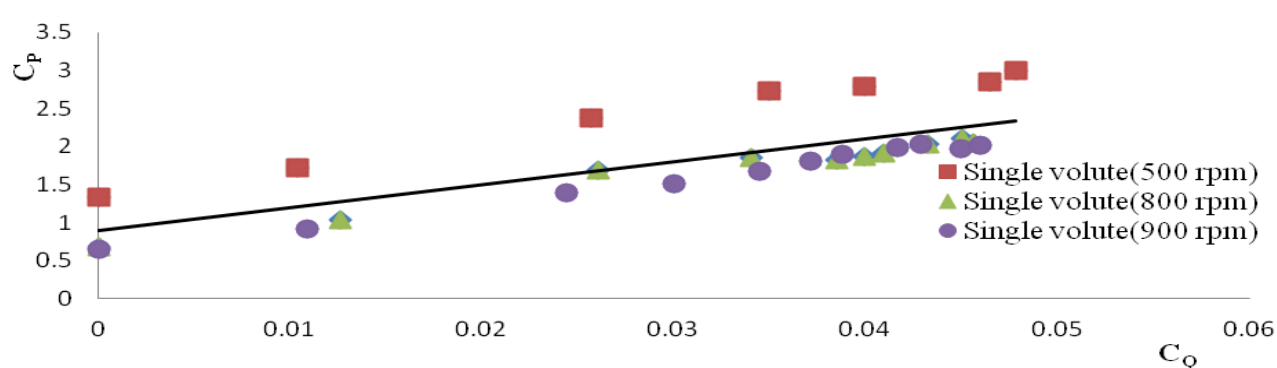

Fig. 3B, Power coefficient (CP) versus flow coefficient (CQ) for single volute pump

Fig. 3C, Variation of efficiency ratio $(\eta / \eta b)$ versus flow coefficient (CQ) for single volute pump

The curves between $C_{h}$ and $C_{Q}$ are plotted for the three pumps in figure 4 . It is noticed that the performances of the three pumps are nearly the same in the three casing types (Single, double and triple volutes). However the values of the efficiency, figure 5, reveal an improvement in efficiency associated with the presence of the volute for example the double volute recorded a $6 \%$ improvement while the triple was $10 \%$ higher than the best efficiency of the single volute.

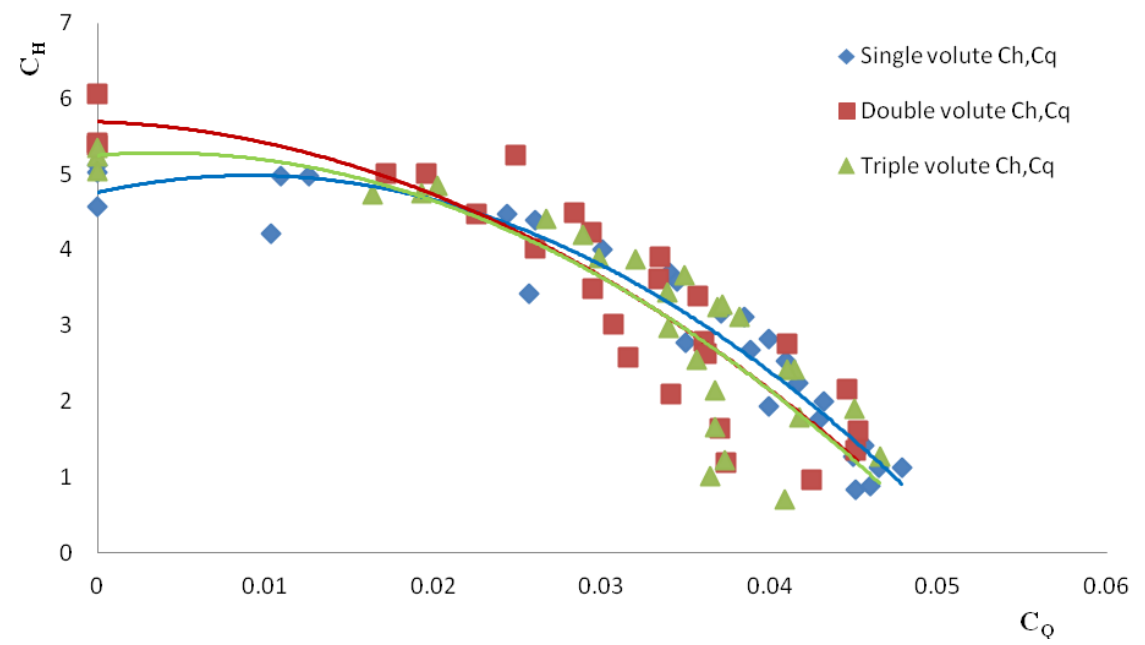

Fig. 4, comparison of Head coefficient $(\mathrm{CH})$ versus flow coefficient $(\mathrm{CQ})$ for single, double and Triple volutes pump. 


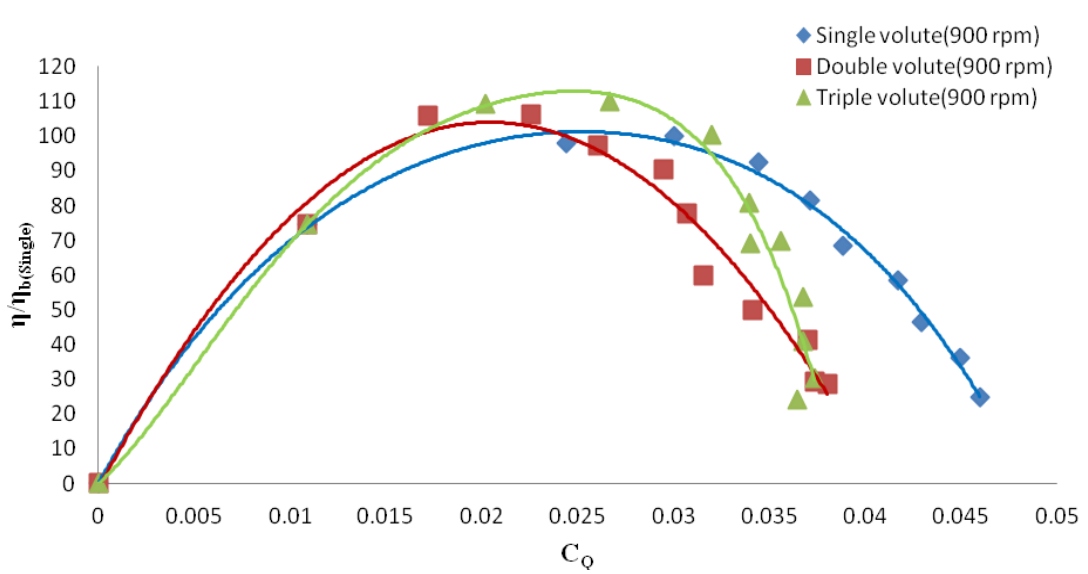

Fig. 5, Comparison of efficiency ratio $\left(\eta / \eta_{\text {bep(Single })}\right)$ versus flow coefficient $\left(\mathbb{C}_{Q}\right)$ for single, double and triple volutes.

\section{2-Pressure distribution}

The pressure distribution along the volute is shown for the three studied cases in figures 6-8). The distribution in case of a single volute is shown in figure 6 for a speed of $900 \mathrm{rpm}$. Three flowrates are chosen to illustrate the distribution in case of shutoff, best efficiency and minimum radial force. The angle (horizontal axis) extends from $0^{\circ}$ the actual tongue to $360^{\circ}$ the inlet to the discharge nozzle. The pressure distribution is continuous and the level of pressure is reduces as the flowrate increases. The forces associated with these cases as well as other cases are presented in the next section. For the double volute, figure 7, the pressure distribution has a clear discontinuity at the angle, of $180^{\circ}$, associate with the tongue of the second volute. In case of triple volute, figure 8 , the pressure distribution has two clear discontinuities at the angles, of $120^{\circ}$ and $240^{\circ}$, associate with the tongues of the second and third volutes.

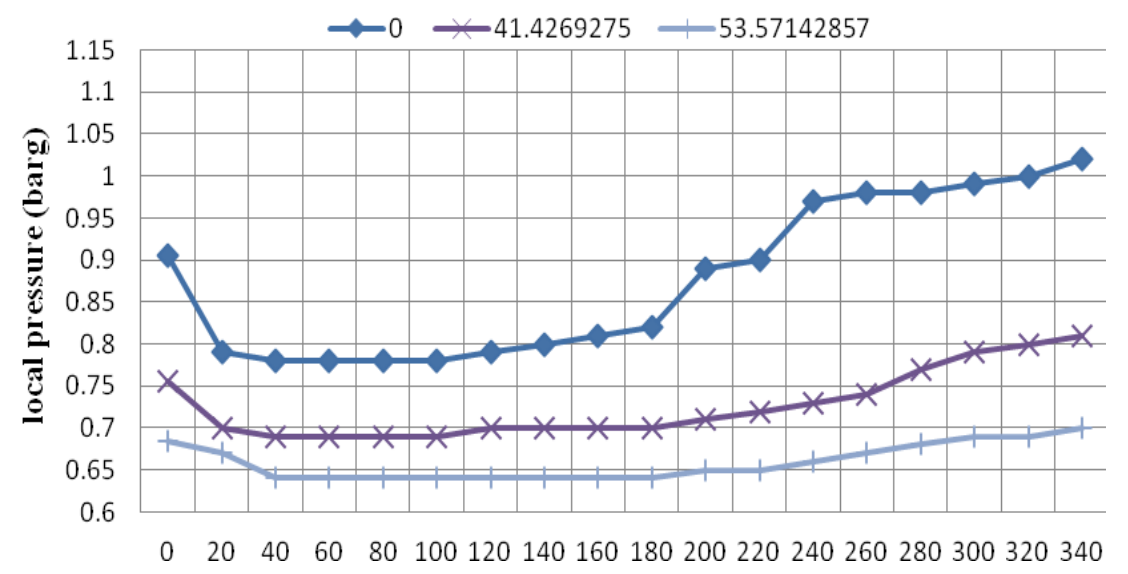

Fig. 6, Pressure distribution along the volute of the single volute pump at 900rpm 


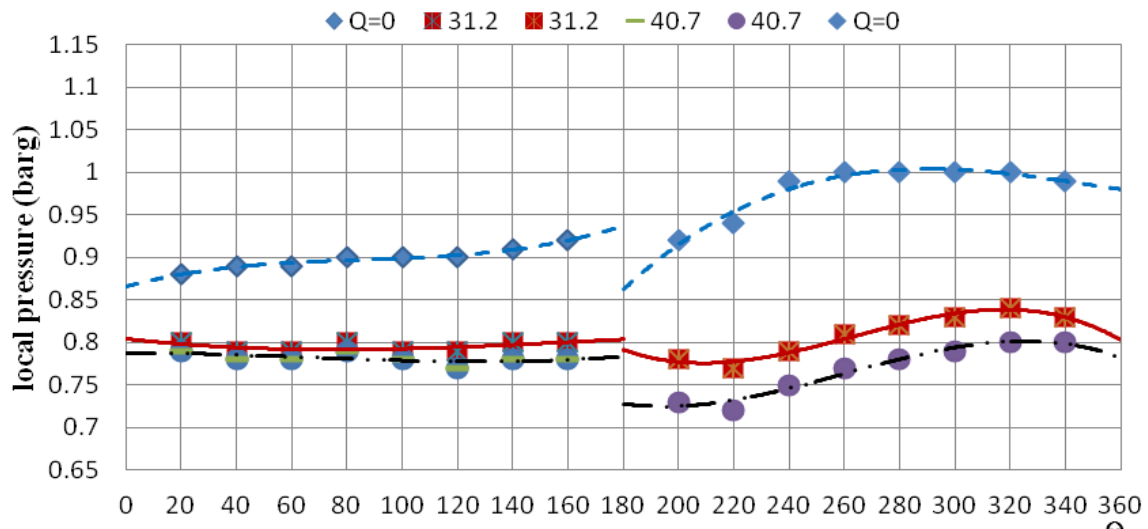

Fig. 7, Pressure distribution along the volute of the double volute pump at 900rpm

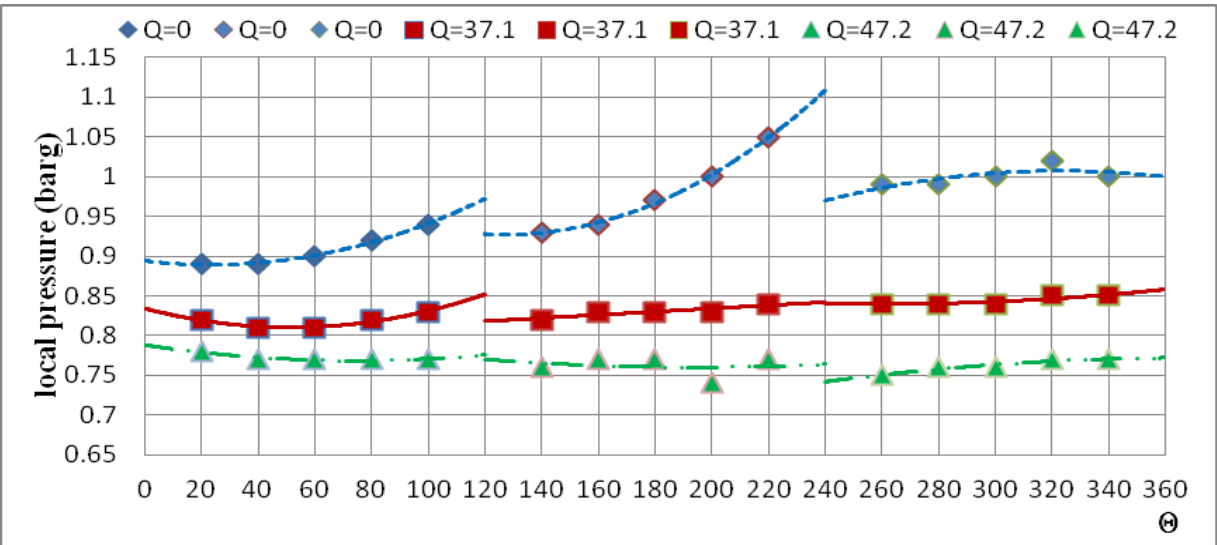

Fig. 8, Distribution along the volute of the triple volute pump at 900rpm

\section{3-RADIAL FORCE}

The pressure measurements presented in the previous section are used to calculate the radial forces. Equation 6 is used to calculate the force components, The integration is done on a curve fit to the data using the trapezoidal rule. Finally the magnitude and direction of the thrust force (Equation 7) are computed for each experimental run. Figure 9 shows the direction of resultant radial forces for single, double and triple-volutes pumps at various flow rates as a ratio of the force at shut off, for the studied pump. The results of the single volute pump compares well with the results of Karassik et al [2]. The curves representing radial thrust of a single volute centrifugal pump at specific speeds of 784 and 1735[1] are overlaid on the current results. The current pump has a specific speed of 1006 and consequently lies between the published results.

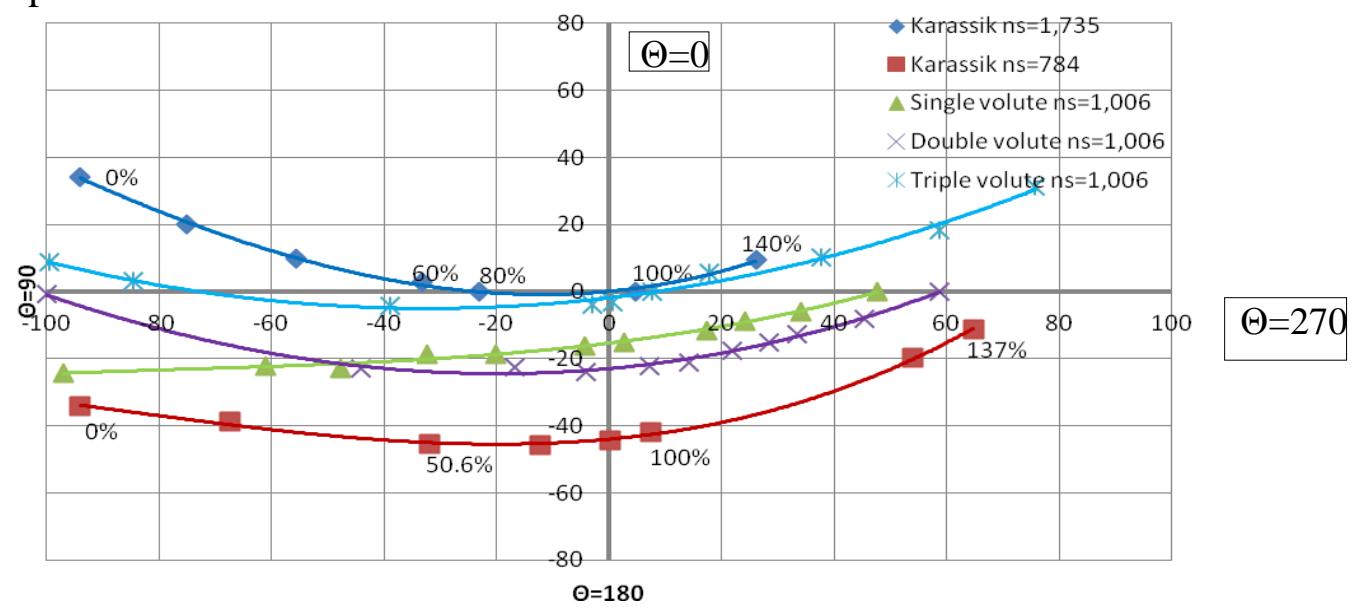

Fig. 9, Polar plot showing direction of resultant radial forces for single, double and triple-volutes pumps at various flow rates 
The radial thrust ratio $(\varnothing)$ is the magnitude of radial force divided by radial force at shutoff for the single volute casing. This ratio is plotted, in figure 10, against the flow ratio which is the flow rate normalized by the flow at best efficiency. The results show that the minimum radial force takes place at a discharge about $25 \%$ higher than the best efficiency, for all the cases. The shutoff force is reduced to $48 \%$ in case of double volute and $28 \%$ in case of triple volute. At flow ratio of $100 \%$ the radial thrust force is reduced to $40 \%$ in case single volute, $14 \%$ in case of double volute, and $11.6 \%$ in case of triple volute. At flow ratio of $125 \%$, the radial thrust force is reduced to $18 \%$ in case of single volute, to $11.5 \%$ in case double volute, and to $1 \%$ in case of triple volute.

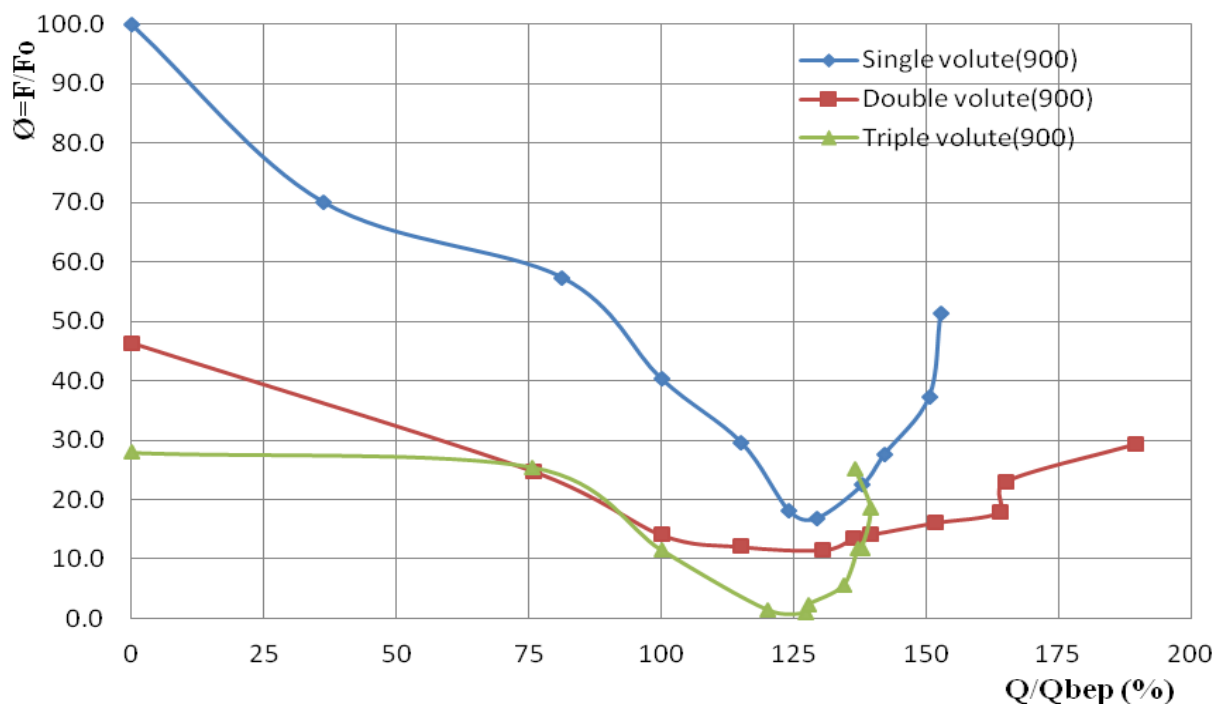

Fig. 10, variation of radial thrust force ratio versus flow ration for single, double and Triple volutes pump at 900 rpm.

The effect of number of volutes on radial thrust force at various flow ratio is shown in figure 11. The radial thrust force at flow ratio of $25 \%$ at triple volute casing reduced by about 20 Newton compared to single volute casing, the radial thrust force at flow ratio of $100 \%$ at triple volute casing reduced by about 10 Newton compared to single volute casing and the radial thrust force at flow ratio of $125 \%$ at triple volute casing reduced by about 7 Newton compared to single volute casing.

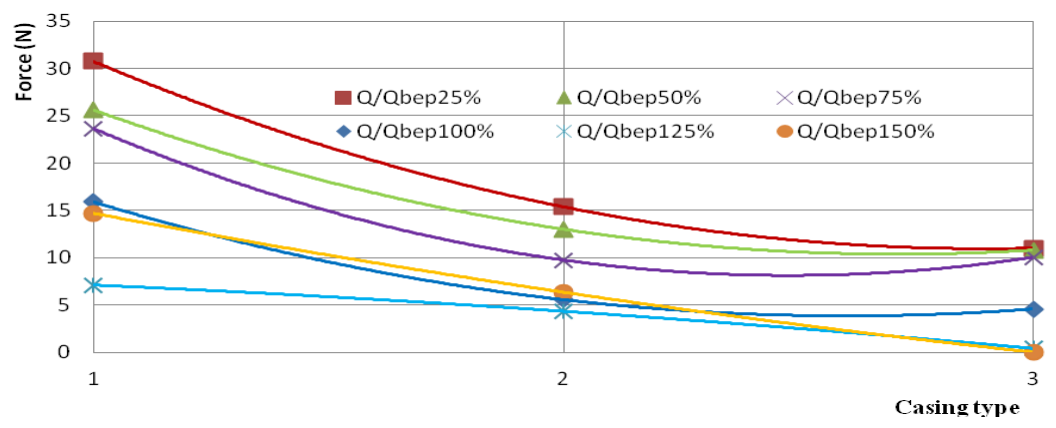

Fig. 11, comparison of the effect of casing type on radial thrust force for different flow ratio.

\section{CONCLUSIONS}

The volute of a centrifugal pump was divided into two and three volutes and the pump was tested under these three conditions. The efficiency was seen to increase by $6 \%$ in case of two volutes and $10 \%$ in case of three volutes. The head and discharge of the pump was not altered significantly: the pump discharged a $54 \mathrm{~m}^{3} / \mathrm{hr}$ against $10 \mathrm{~m}$ head in all cases. The pressure distribution was used to calculate the radial force in all cases. The results agreed with the published results for a single volute. The use of the double and triple volutes reduced the radial thrust at shutoff to $48 \%$, and $25 \%$ respectively of its value corresponding with shutoff of single volute, respectively. The radial thrust ratio took place a $125 \%$ of the design flow 
rate. This minimum ratio was $18 \%$ in case of single volute, $11.5 \%$ in case of double volute and $1 \%$ in case of triple volute.

\section{REFERENCES:}

1- Stepanoff, A.J., Centrifugal \& Axial Flow Pumps, John Wiley and Sons, Inc., New York, (1975).

2- Igor J. Karassik, Joseph P. Messina, Paul Cooper, and Charles C. Heald," Pump Handbook", McGrew - Hill, (2001).

3- Agostinelli AA, Nobles DD, Mockridge CR. "An Experimental Investigation of Radial Thrust in Centrifugal Pumps", ASME. J. Eng. Power. 1960;82(2):120-125. doi:10.1115/1.3672726.

4- Val S. Lobanoff, and Robert R. Ross," Centrifugal Pumps Design \& Applications", Gulf Publishing Company, Houston, TX. (1985)

5- Hazem Mazhar, "Effect of Some Design Parameters on the Performance of Double Volute Centrifugal Pumps", M.Sc. Thesis, Ain Shams University 2007.

6- Daniel O. Baun, Lutz Köstner, Ronald D. Flack, "Effect of Relative Impeller-to-Volute Position on Hydraulic Efficiency \& Static Radial Force Distribution In A Circular Volute Centrifugal Pump", The American Society of Mechanical Engineers, journal of J. Fluids Eng., Sept. 2000,Volume 122, Issue 3, 598

7- The Patent Office, UK, UK Patent Application GB 2416003 A, (2006).

8- Morgenroth MM, Weaver DS. "Sound Generation by a Centrifugal Pump at Blade Passing Frequency", ASME. J. Turbomach. 1998;120(4):736-743. doi:10.1115/1.2841784.

9- M. Behzad, A. R. Bastami, M. Maassoumian, "Fault Diagnosis of a Centrifugal Pump by Vibration Analysis", ASME 7th Biennial Conference on Engineering Systems Design and Analysis, ESDA2004-58534 pp. 221-226, Volume 3, July 19-22, 2004

10- Masanori AOKI. "Instantaneous Interblade Pressure Distributions and Fluctuating Radial Thrust in a Single-blade Centrifugal Pump", Bulletin of JSME, Vol. 27 No. 233 P 24132420, November 1984.

11- José González, "Unsteady Flow Structure and Global Variables in a Centrifugal Pump", Journal of Fluids Engineering, Transactions of the ASME, Vol. 128 / 945, Sept., 2006

12- Jose Gonzales, Jorge Parrondo, Carlos Santolaria, and Eduardo Blanco, "Steady and Unsteady Radial Forces for a Centrifugal Pump With Impeller to Tongue Gap Variation”, ASME Journal Fluids Eng., Volume 128, May 2006.

13- Pengcheng Guo, Xingqi Luo, and Weili Liao, "Numerical Investigation on ImpellerVolute Interaction in the Centrifugal Pump With Radial Gap and Tongue Profile Variation", ASME, Fluids Engineering Division Summer Meeting collocated with the Heat Transfer, Energy Sustainability FEDSM2008-55257 pp. 217-224, 2008.

14- Austin H. Church, Centrifugal pumps and blowers, John Wiley \& Sons Inc, 1947. 